Revista Tecné, Episteme y Didaxis: TED. Año 2014, Número Extraordinario. ISSN Impreso: 0121-3814, ISSN web: 2323-0126

Memorias, Sexto Congreso Internacional sobre Formación de Profesores de Ciencias. 08 al 10 de octubre de 2014, Bogotá

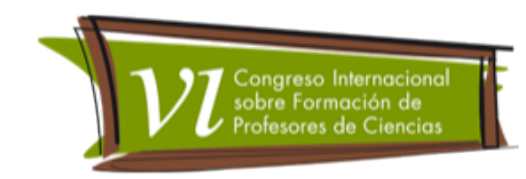

\title{
Fortalecimiento Del Conocimiento De La Etnobotánica En Las Plantas Medicinales Desde El Currículo
}

Delgado Conde, Karla Natalia'; Díaz Martínez, María Alejandra².

Categoría 2. Trabajo de investigación

\section{Resumen}

La Etnobotánica es una herramienta útil para el rescate y reconocimiento de los saberes populares. Esta no se contempla en el currículo pudiendo aportar en la enseñanza de las ciencias en lo referente al uso de las plantas medicinales. Buscamos fortalecer el saber etnobotánico en estudiantes del grado quinto de la Institución Educativa Departamental Tierra de Promisión de la ciudad de Neiva Huila, a través de una intervención curricular en el aula. Mediante enfoque cualitativo de tipo descriptivo y análisis de contenido de la información proveniente de documentos curriculares, cuestionarios de preguntas abiertas, entrevistas focales y actividades diseñadas y aplicadas en el aula. Dentro de los resultados parciales los estudiantes reconocen algunos usos de las plantas medicinales de su institución debido a la transmisión oral por parte de sus padres o familia.

\section{Palabras claves}

Currículo, ciencias naturales, etnobotánica, plantas medicinales.

\section{Objetivo General}

Fortalecer los conocimientos de los niños y niñas del grado $5^{\circ}$ de la I.E. Departamental Tierra de Promisión de la ciudad de Neiva, sobre el uso de las plantas medicinales de su entorno escolar y familiar para la conservación de éstas manejando contenidos actitudinales, conceptuales, procedimentales en la enseñanza de las ciencias naturales para la conservación de su identidad y cultura.

\footnotetext{
1 Universidad Surcolombiana natusha-912@hotmail.com.

2 Universidad Surcolombiana alejitadima24@hotmail.com.
} 
Revista Tecné, Episteme y Didaxis: TED. Año 2014, Número Extraordinario. ISSN Impreso: 0121-3814, ISSN web: 2323-0126

Memorias, Sexto Congreso Internacional sobre Formación de Profesores de Ciencias. 08 al 10 de octubre de 2014, Bogotá

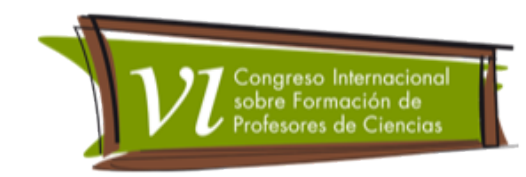

\section{Objetivos Específicos}

Identificar las características del currículo en cuanto a la enseñanza de las ciencias naturales y su relación con la etnobotánica de los usos medicinales.

Conocer los saberes que tienen los niños y las niñas acerca del uso de las plantas medicinales de su entorno escolar y familiar.

Diseñar, aplicar y evaluar una serie de actividades con base a los saberes de los estudiantes y a las características encontradas sobre el currículo en la enseñanza de las ciencias.

\section{Marco Teórico}

La etnobotánica es considerada como "una disciplina interpretativa y asociativa, que busca, utiliza, y une las interrelaciones entre las Sociedades Humanas y las Plantas" (Portéres, 1961).También la Etnobotánica es considerada como ciencia aplicada integralmente entre el manejo de la vegetación y la cultura, forma una herramienta útil para el rescate y reconocimiento de los saberes populares.

A través de la enseñanza de la etnobotánica en el aula de clase, se busca despertar en los niños el interés por conocer y aprender los secretos que la naturaleza ha ido enseñando lentamente a sus antepasados sobre cómo aprovecharla para que ellos como futuros administradores de esta sepan valorarla, respetarla y cuidarla en sus núcleos familiares y de allí a su comunidad.

La escuela como institución puede considerarse como un sitio para rescatar los saberes populares a través de la etnobotánica y la enseñanza de las ciencias naturales ya que es importante para el desarrollo del pensamiento, la adquisición de conocimiento y actitudes reflexivas y críticas que permitan afrontar los desafíos de la sociedad actual. Esto se expresa a través de las finalidades de la ley 115 (1994) en su artículo 5 el cual se refiere al estudio y la comprensión crítica de la cultura nacional y de la diversidad étnica y cultural del país, como fundamento de la unidad nacional y de su identidad. Esto significa que a la escuela corresponde el estudio de la riqueza cultural y la diversidad étnica del país, abarcando los conocimientos que nuestras sociedades tienen de la riqueza biológica del territorio. Además organizaciones como la UNESCO ha reconocido, defendido y justificado la importancia de incorporar las ciencias en el curriculum de la educación primaria. Algunos de estos aspectos propuestos por Harlen W., 1994, expresa: "Contribuir a la comprensión del mundo que rodea a los niños". 
Revista Tecné, Episteme y Didaxis: TED. Año 2014, Número Extraordinario. ISSN Impreso: 0121-3814, ISSN web: 2323-0126

Memorias, Sexto Congreso Internacional sobre Formación de Profesores de Ciencias. 08 al 10 de octubre de 2014, Bogotá

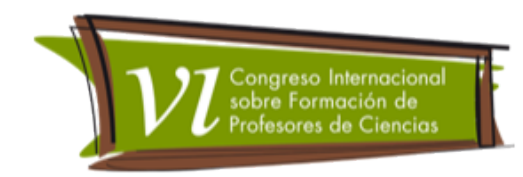

Comprensión que se va ampliando y fortaleciendo a medida que crece la misma experiencia del niño. Al revisar el currículo de la escuela donde llevaremos a cabo la investigación propondremos desde un currículo no solo planeado, sino aplicado y evaluado una serie de actividades donde se relaciones la enseñanza de las ciencias naturales y la etnobotánica en lo que respecta a las plantas medicinales.

Para lograr lo anterior se propone una enseñanza con un enfoque constructivista que permite la participación activa del estudiante no solo desde lo volitivo sino desde lo cognoscitivos desarrolla una serie de contenidos útiles en la formación de chicos y chicas. La enseñanza de las ciencias naturales para nuestro caso la biología tiene como finalidades el desarrollo de actitudes o comportamientos personales adecuados en relación con el medio natural que significan el cuidado y respeto por este, en este caso las plantas de su entorno, la escuela (Banet, 2000) y valores como el reconocimiento de los saberes de sus abuelos como parte de la identidad cultural.

En cuanto a lo conceptual el estudio sobre las plantas y sus utilidades, en cuanto a los contenidos procedimentales según Coll (1992) podemos hablar por una parte de las destrezas cognitivas, de las estrategias superiores de pensamiento que permite aprender a aprender, entre estas están la posibilidad de clasificar según criterios establecidos.

Estos contenidos actitudinales, conceptuales y procedimentales se pueden desarrollar introduciendo la etnobotánica específicamente el estudio de las plantas medicinales en el currículo de primaria en la enseñanza de las ciencias naturales.

\section{Metodología}

Con un enfoque cualitativo interpretando la realidad escolar al desarrollo de la propuesta curricular en el aula, surgida en esta investigación en el marco de un estudio de caso, se eligió dos técnicas: la revisión de documentos curriculares (PEl, planes de área) de la institución educativa y realización de encuestas a estudiantes para determinar lo que saben sobre plantas medicinales de su entorno, entrevistas a grupo focal. En la recolección de datos se diseñaron guías de lápiz y papel con preguntas abiertas; cuestionario tomado de la Fundación Multitalller de la Universidad del Valle. Aplicado a una muestra de 35 estudiantes de grado $5^{\circ}$ de básica primaria. 
Revista Tecné, Episteme y Didaxis: TED. Año 2014, Número Extraordinario. ISSN Impreso: 0121-3814, ISSN web: 2323-0126

Memorias, Sexto Congreso Internacional sobre Formación de Profesores de Ciencias. 08 al 10 de octubre de 2014, Bogotá

Se establecieron categorías: finalidad de enseñanza de las ciencias naturales, contenidos conceptuales, procedimentales y actitudinales, plantas medicinales, usos de las plantas medicinales.

En un primer momento el estudio del currículo de grado $5^{\circ}$ y los saberes de los estudiantes sobre plantas medicinales de su entorno escolar y familiar. Un segundo momento de análisis de la información recolectada para diseñar las actividades para intervenir el aula y un Tercer momento de aplicación y evaluación de la intervención para comprobar si la propuesta permitió llegar al objetivo general.

\section{Resultados Parciales}

Primer momento: se revisó los documentos curriculares de $5^{\circ}$. A continuación los resultados de la aplicación de la encuesta antes mencionada a cada estudiante

Actividad $\mathbf{N}^{\circ} 1$ Conocimientos de los estudiantes sobre plantas medicinales.

Nombre: Grado:

Leo y analizo el siguiente texto:

El ser humano utiliza las plantas en diferentes actividades como en la alimentación, en la medicina, en la industria o como ornamentales.

Alimenticias: Son fuente de alimento no solo para el ser humano sino también para los animales; entre ellas podemos mencionar las frutas, las verduras u hortalizas, y las legumbres como el frijol y la alverja. Medicinales: algunas plantas son utilizadas como remedios caseros, otras son llevadas al laboratorio para obtener los derivados farmacológicos o drogas. Ornamentales: nos ayudan a embellecer la casa, los jardines, los altares o las plazas.

Industriales: se utilizan en la fabricación de productos útiles para las personas, como la obtención de hilos, vinos, aceites, perfumes, llantas, sombreros. 
Revista Tecné, Episteme y Didaxis: TED. Año 2014, Número Extraordinario. ISSN Impreso: 0121-3814, ISSN web: 2323-0126

Memorias, Sexto Congreso Internacional sobre Formación de Profesores de Ciencias. 08 al 10 de octubre de 2014, Bogotá

1. Contesto

las

siguientes

preguntas:

a. ¿̇ué plantas utilizan en mi casa cuando alguien sufre un dolor de estómago?

b. ¿Cómo se llama la planta que utiliza mi mama cuando tengo fiebre?

c. Cuando me caigo y me golpeo ¿̇Qué plantas me ayudan a sanar?

Análisis de las respuestas a las preguntas del lar Actividad según los gráficos: 1,2 y 3.

Grafico 1. Pregunta a.

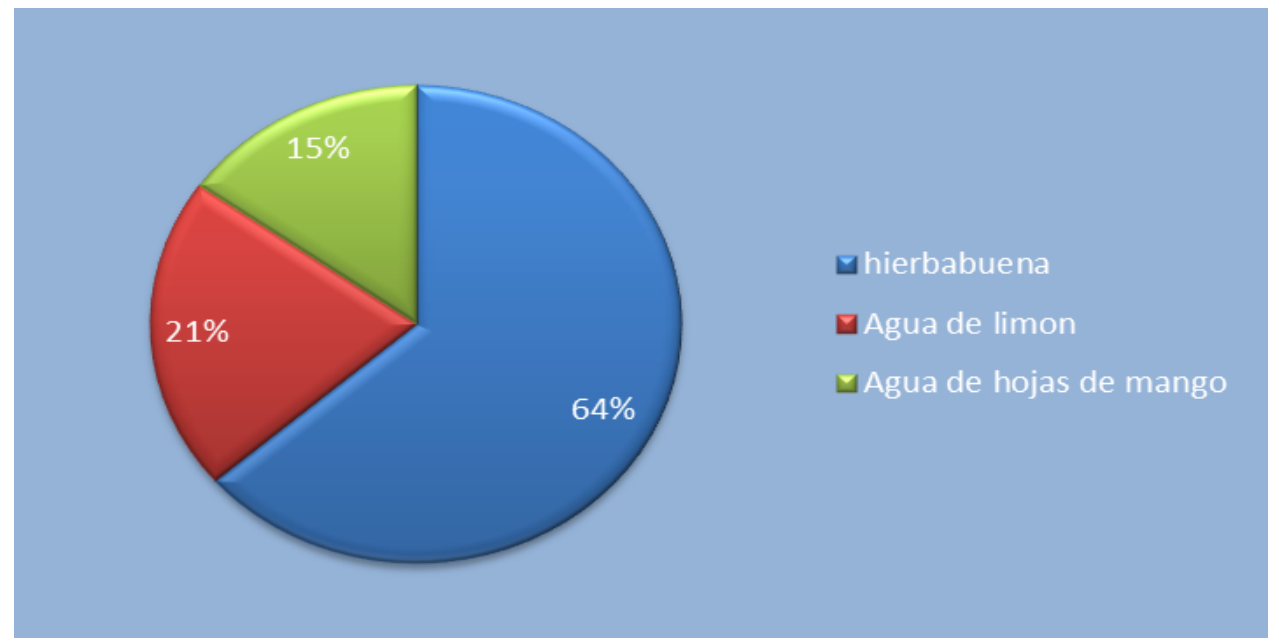

Hay un dato curioso ya que solo el $15 \%$ de los estudiantes utilizan menos las hojas de mango y que es esta la que más se conoce, para este tipo de dolor según la literatura y los manuales de la medicina natural. Para este caso nos damos cuenta que la hierbabuena es una planta que se utiliza para el caso de dolor de estómago de los estudiantes. 
Revista Tecné, Episteme y Didaxis: TED. Año 2014, Número Extraordinario. ISSN Impreso: 0121-3814, ISSN web: 2323-0126

Memorias, Sexto Congreso Internacional sobre Formación de Profesores de Ciencias. 08 al 10 de octubre de 2014, Bogotá

Gráfico 2. Pregunta b.

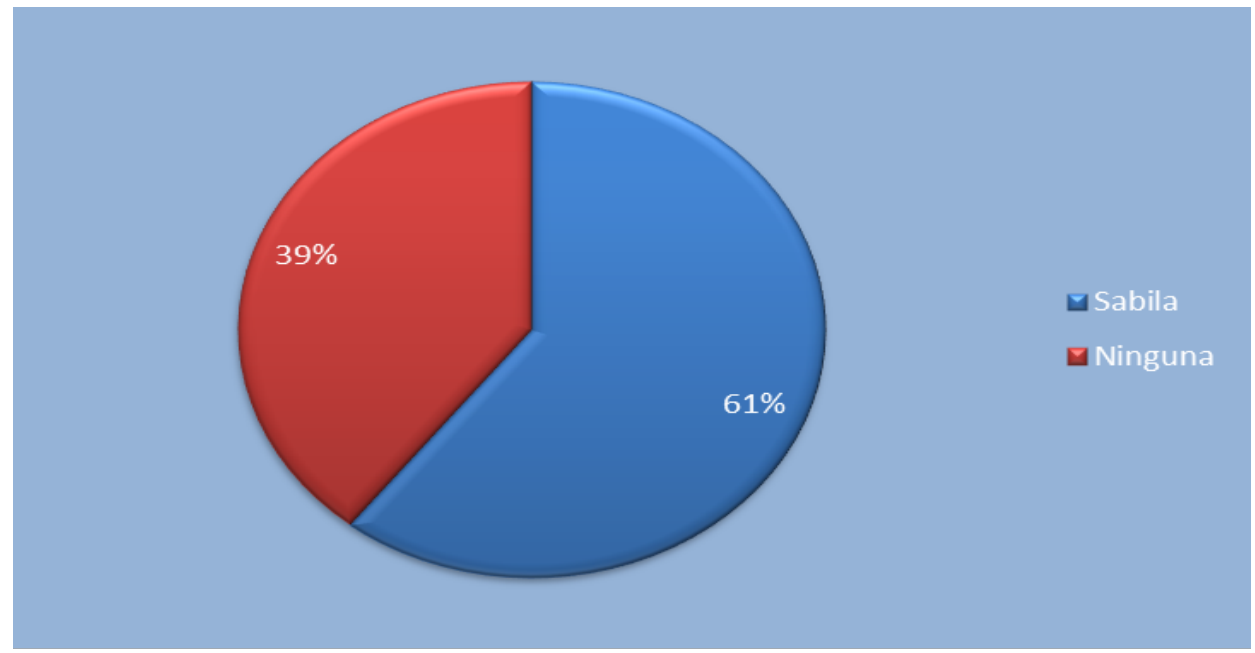

El 39\% de los estudiantes no han tenido ningún contacto con plantas que alivien esta enfermedad, es claro ver como la sábila es aquella planta que se utiliza para este tipo de dolencia como es la fiebre.

Gráfico 3. Pregunta C.

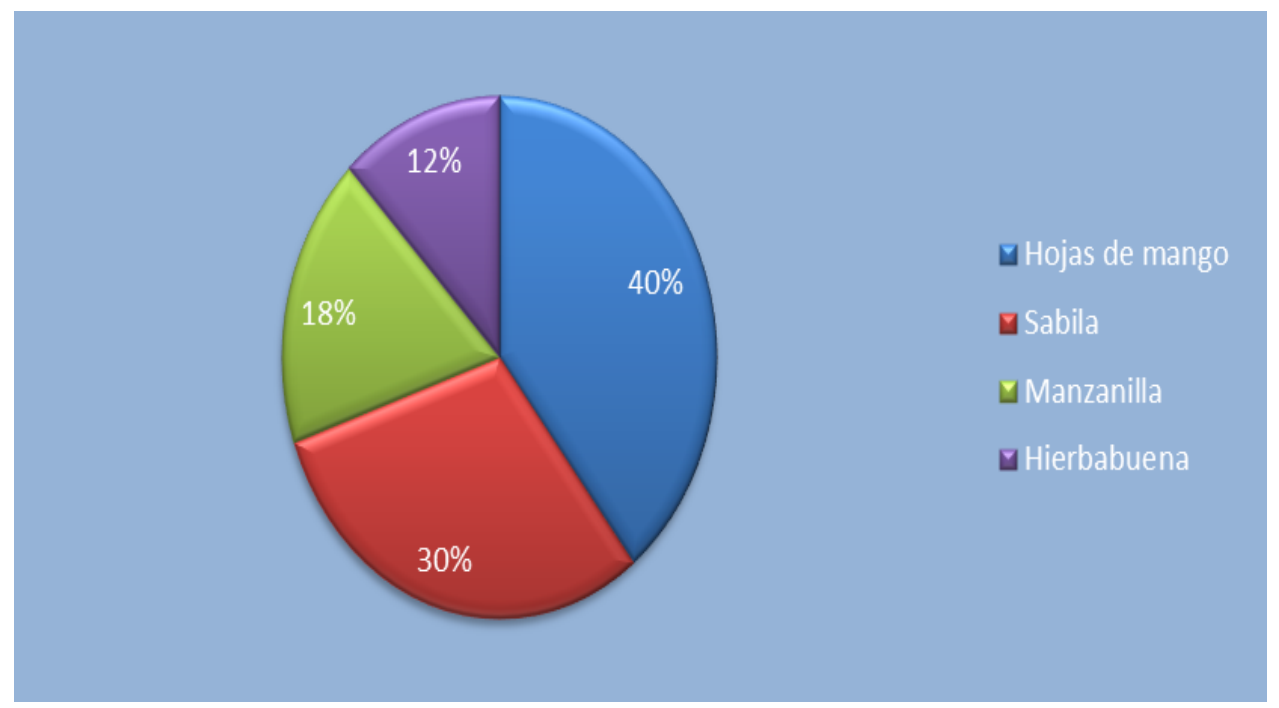

Se observa que la más sobresaliente es la hoja de mango con un $40 \%$, tiene mayor utilidad para los niños en cuanto a los golpes seguidamente para otra mayoría es la sábila, manzanilla y hierbabuena, asociando este tipo de plantas con las enfermedades y golpes más comunes en niños. 
Revista Tecné, Episteme y Didaxis: TED. Año 2014, Número Extraordinario. ISSN Impreso: 0121-3814, ISSN web: 2323-0126

Memorias, Sexto Congreso Internacional sobre Formación de Profesores de Ciencias. 08 al 10 de octubre de 2014, Bogotá

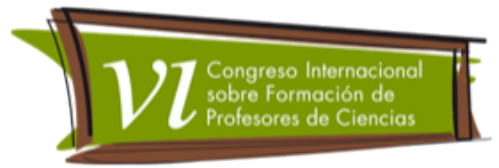

Para conocer lo que los estudiantes sabían sobre las plantas de la escuela se realizó una entrevista al grupo de 35 estudiantes que se consideró el grupo focal.

Actividad 2: ¿Conoces las plantas y árboles de tu escuela?

En esta actividad se logra cambiar el salón de clases por un salón más natural, "el patio" de la escuela, donde se consigue enriquecer las vivencias de los niños, se procurará que ellos se contacten lo más directamente posible con el entorno que los rodea y así analicen lo que observan, pregunten y expresen sus ideas. Es un espacio donde el profesor requiere ser muy perceptivo con las inquietudes e interrogantes que tengan los niños, para que de esta manera pueda utilizarlos para fomentar un aprendizaje más didáctico.

A la hora de realizar el recorrido por el patio del colegio, con el fin de que reconocieran que plantas y árboles que habían allí, se les pregunto a los niños si conocían algunos de ellas, y la gran mayoría de los niños sabían que arboles eran y de los que no conocían o que no recordaban se les hablo; hasta terminar el recorrido y sentarnos en círculo para compartir experiencias vivencias particulares. La actividad se tornó muy interesante ya que todos los niños querían hablar y comentar lo que sabían, iniciaron identificando de nuevo cuales y cuantos arboles habían, y asociaron cada uno de ellos con sus usos y sus anécdotas; en su gran mayoría los niños coincidieron con la parte teórica que nos muestra los usos de cada una de estas plantas, reflejándose que la idea general la tenían, un ejemplo de ello es cuando la estudiante un nos habla del palo de cruz, y nos dice que en su casa la corteza de este árbol se corta hacia arriba y es utilizada por las mujeres para el dolor menstrual. De esta forma los niños nos dan a entender que tienen estos conocimientos por sus padres, abuelos o familiares que utilizan estas plantas de manera medicinal según el problema que tengan.

Tabla 1.Comparación de los conocimientos sobre las plantas de la escuela.

\begin{tabular}{|l|l|l|l|}
\hline $\begin{array}{l}\text { Nombre común de } \\
\text { la planta }\end{array}$ & Familia & $\begin{array}{l}\text { No Niños que saben } \\
\text { SU uso }\end{array}$ & Que usos saben. \\
\hline Limoncillo & Rutaceae & $\begin{array}{l}\text { Los alumnos en la } \\
\text { mayoría no saben. }\end{array}$ & $\begin{array}{l}\text { Casi no encontraron los de estas. Se le aclaro } \\
\text { uso eran ornamentales } \\
\text { que erame }\end{array}$ \\
\hline
\end{tabular}


Revista Tecné, Episteme y Didaxis: TED. Año 2014, Número Extraordinario. ISSN Impreso: 0121-3814, ISSN web: 2323-0126

Memorias, Sexto Congreso Internacional sobre Formación de Profesores de Ciencias. 08 al 10 de octubre de 2014, Bogotá

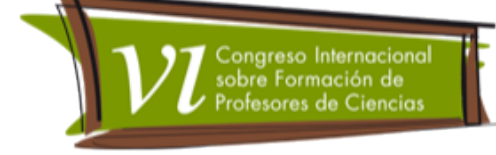

\begin{tabular}{|c|c|c|c|}
\hline Pomarroso & Mirtaceae & 20 Niños & $\begin{array}{l}\text { Los niños acertaron en } \\
\text { algunos usos medicinales } \\
\text { relacionados con el peso y } \\
\text { la fiebre. }\end{array}$ \\
\hline Yarumo & Urticaceae & 2 Niños & $\begin{array}{l}\text { Los niños acertaron con los } \\
\text { usos ya que según sus } \\
\text { abuelos sirve para } \\
\text { dolencias de pulmones y } \\
\text { diurético. }\end{array}$ \\
\hline Vainillo & $\begin{array}{l}\text { Fabáceae/ } \\
\text { Cesalpinióideas }\end{array}$ & Ninguno & $\begin{array}{l}\text { No conocen sus } \\
\text { propiedades medicinales. }\end{array}$ \\
\hline Almendrón & Combretáceae & 15 Niños & $\begin{array}{l}\text { Afirman que el fruto es muy } \\
\text { rico en el cual le } \\
\text { denominan coco y que en } \\
\text { algunos casos sus padres lo } \\
\text { utilizan para la diarrea. }\end{array}$ \\
\hline Mamoncillo & Sapindáceae & 35 Niños & $\begin{array}{l}\text { Afirman que el fruto del } \\
\text { mamoncillo es comestible. } \\
\text { Ninguno lo describe como } \\
\text { medicinal. }\end{array}$ \\
\hline Mango & Anacardiáceae & $35-17$ & $\begin{array}{l}\text { Su uso medicinal lo asocia } \\
\text { al mal de estómago. }\end{array}$ \\
\hline Sábila & Xantorreáceae & 35 Niños & $\begin{array}{l}\text { Por los cuales relacionan } \\
\text { esta planta por aliviar } \\
\text { dolores, controlar la fiebre } \\
\text { entre otros } \\
\text { proporcionados usos } \\
\text { información de la } \\
\text { actividad. }\end{array}$ \\
\hline
\end{tabular}


Revista Tecné, Episteme y Didaxis: TED. Año 2014, Número Extraordinario. ISSN Impreso: 0121-3814, ISSN web: 2323-0126

Memorias, Sexto Congreso Internacional sobre Formación de Profesores de Ciencias. 08 al 10 de octubre de 2014, Bogotá
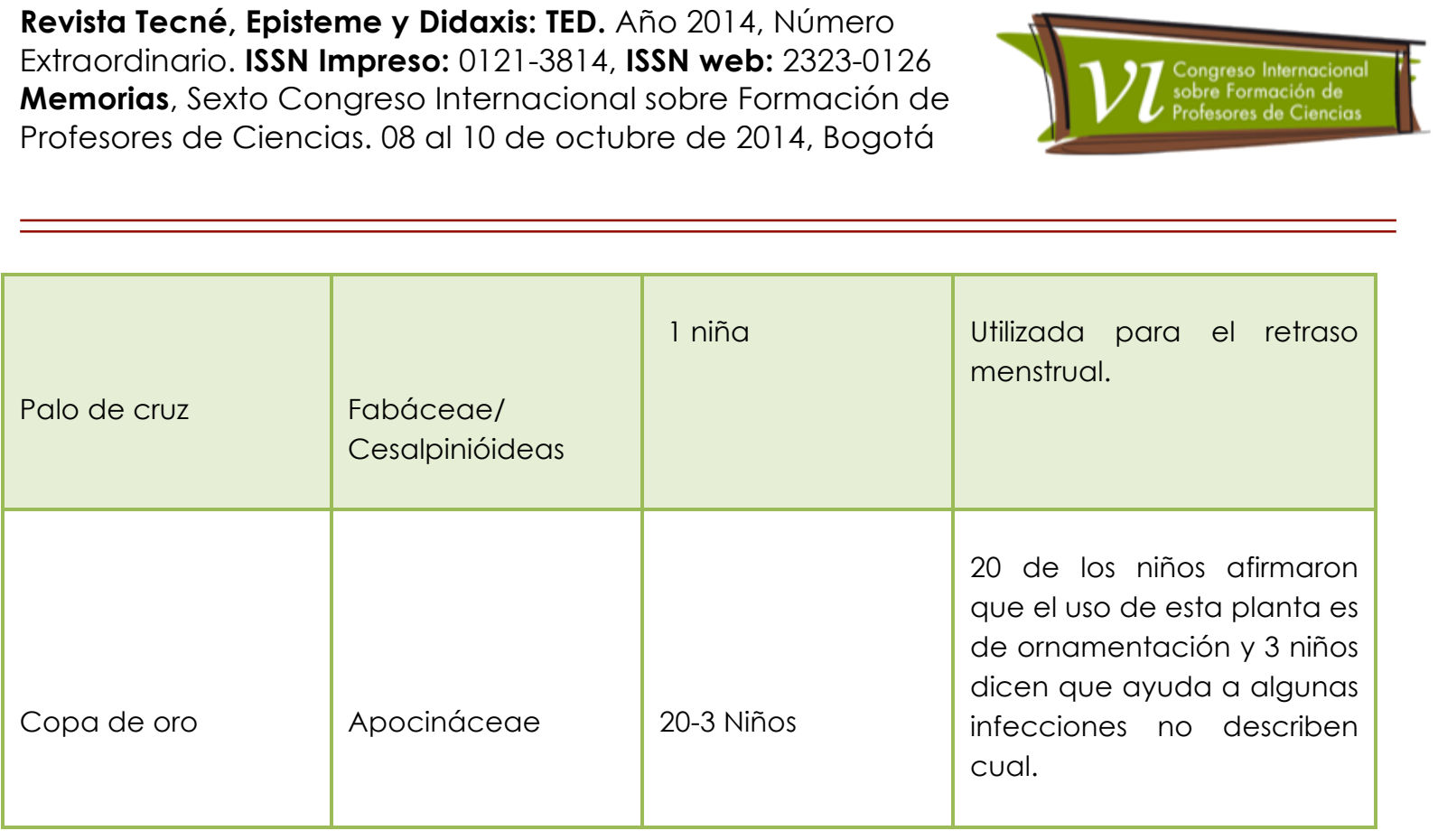

Se infiere finalmente que estos conocimientos los han adquirido en casa, con sus familiares al ver y al tener la curiosidad por lo que los mayores hacen, llevándolo a la vida cotidiana y teniendo un aprendizaje en el cual lo pueden fortalecer en sus clases. Estos resultados parciales nos van dando una idea de las actividades que podemos diseñar y aplicar en el aula.

\section{Conclusiones Parciales}

Las actividades propuestas en la metodología para recoger información sobre los conocimientos de los estudiantes sobre las plantas medicinales han permitido identificar las plantas que ellos conocen a partir de la relación con sus padres y del uso que le dan en sus hogares. Se puede observar que los estudiantes conocen en un gran número las plantas de la escuela y en el entorno familiar manejan algunas plantas según la frecuencia de uso medicinal para enfrentar problemas de salud.

El fortalecer los conocimientos de los niños sobre el uso de las plantas medicinales se logra recuperar parte de la identidad y valores que mantienen vivas nuestras costumbres, al igual que el respeto que lleva al niño a entender que el entorno natural es muy importante y que las plantas que tienen a su lado poseen unos usos que les ofrece beneficios, de tal manera que las hagan propias y tomen actitudes para conservarlo.

\section{Referencias Bibliográficas}

Banet. (2000). L enseñanza y el aprendizaje del conocimiento biológico. Didáctica de las ciencias experimentales. Madrid: Marfil, pág. 449-478 
Revista Tecné, Episteme y Didaxis: TED. Año 2014, Número Extraordinario. ISSN Impreso: 0121-3814, ISSN web: 2323-0126

Memorias, Sexto Congreso Internacional sobre Formación de Profesores de Ciencias. 08 al 10 de octubre de 2014, Bogotá

Coll y Sarabia (1992), Los Contenidos de la Reforma. Enseñanza y Aprendizaje de Conceptos, Procedimiento y Actitudes. Santillana

De Educación, L. G. (1994). Ley 115 febrero 8 de 1994. Ediciones Populares.

Fundación Multitaller de la Universidad del Valle. (s.f.). Escuela Nueva .Obtenido de Ciencias Naturales 4: http://www.colombiaaprende.edu.co/html/TVeducativa/1600/articles91028_actividad1.pdf

García, S.L.W (2011).Manual de herramientas etnobotánicas relativas a la conservación y el uso sostenible de los recursos vegetales. Obtenido de http://www.ibiologia.unam.mx/gela/manualetnobot.pdf

Universidad Nacional de Colombia, Herbario. Obtenido de http://www.biovirtual.unal.edu.co/nombrescomunes/index.php?option=com _wrapper\&view=wrapper\&ltemid=3\&lang=es

Usos de las plantas medicinales. Obtenido de http://salud.ellasabe.com/plantasmedicinales/ 